\title{
NATURAL FREQUENCY ANALYSIS OF CRACKED BEAM
}

\author{
NGUYen TiEN KHIEM, DaO NHU MaI \\ Institute of Mechanics, Hanoi Vietnam
}

\begin{abstract}
The model of cracked one-dimensional structure has been treated as two uniform beams connected by an equivalent rotation spring at the crack location. The frequency equation in bending vibration of the system is obtained in general form for arbitrary boundary conditions at both ends used for analysing the natural frequencies as function of crack position and magnitude. This investigation allows to carry out general procedure for identification of position as well as magnitude of the crack by natural frequencies measured experimentally.
\end{abstract}

\section{Introduction}

The crack occurred in vibrating members (one-dimentional structures) can be treated in different manners. Yuen [1] characterized the crack by a local change in modulus of elasticity and used the FEM to study the eigenprameters of cracked cantilever. Adams et al [2] represented crack as change in axial vibration receptance of a bar at the crack location. Dimaroganas et al. $[3,4,5]$ suggested to model the crack by an equivalent rotation spring, connecting the beam segments on both sides of the crack location. The last crack model has been used for studying effect of crack on the vibration eigenparameters of beam in particular cases of boundary supports. For example, natural frequencies were analyzed in dependence on crack parameters for cantilever in [6] and for simply supported beam in [7]. General investigation of cracked beam was done in $[9,10]$.

In present paper the Dimaroganas's crack model is utilized to develop general (independently on boundary conditions) procedure for analyzing influence of the crack location and magnitude on the natural frequencies. At first, general equation for frequency parameter $\lambda$ is derived independently upon the boundary conditions of supports, then it is used for studying the dependence of the $\lambda$ on the crack parameters: its sit $x$ and magnitude $\beta$ for classical cases of the boundary conditions.

Notation

$E$ - Young's modulus;

$E$ - Cross section area;

$J$ - Moment of inertia;

$\rho$ - Density;

$L$ - Total length;

$$
\begin{aligned}
& \nu \text { - Torsion stiffness of spring; } \\
& f \text { - Frequency }(H z) ; \\
& \omega=2 \pi f \\
& \lambda \text { - Frequency parameter; } \\
& \beta=E J / \nu L-\text { Magnitude of dramage; }
\end{aligned}
$$

\section{Model of cracked beam}

Consider a damaged beam with structural parameters: $E, F, J, \rho, L$ for arbitrary support conditions at the ends. Let crack be located at some unknown position $y_{0}$, which divides the beam 
into 2 parts 1,2 as shown in Fig. 1a. According to $[3,4,5]$, the crack may be represented by a torsional spring connecting the specimens of beam at the crack position. Stiffness $\nu$ of the spring can be calculated by the formulas

$$
\nu=\frac{1}{C}, \quad C=\frac{5.346 h}{E J} I\left(\frac{a}{h}\right)
$$

here, $h$ - the height of cross section of the beam, $a$ - the depth of the crack and function $I(z)$ has the form

$I(z)=1.8624 z^{2}-3.95 z^{3}+16.375 z^{4}-37.226 z^{5}+76.81 z^{6}-126.9 z^{7}+172 z^{8}-143.97 z^{9}+66.56 z^{10}$

Introducing magnitude of the crack by the value: $\beta=E J / \nu L$, we have

$$
\beta=\frac{5.346 h}{L} I\left(\frac{a}{h}\right)
$$

Therefore, two limiting cases can be underlined: Undamaged beam: $\beta=0$ (or $\nu=\infty$ ) because for $a=0$ function $I(a / h)=0$, and completely damaged one, i.e. $a=h$, for which

$$
\beta=\beta_{\infty}=5.346(h / L) I(1)=115.15(h / L)
$$

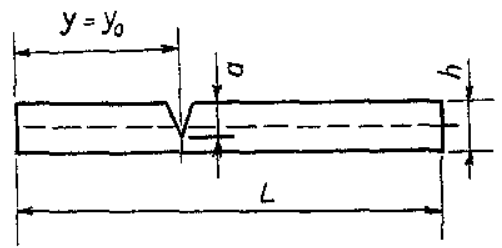

a)

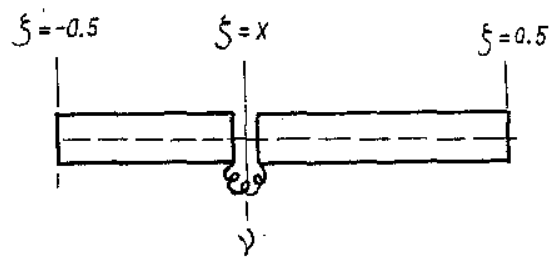

b)

Fig. 1. Model of the cracked beam

\section{Frequency equation}

Condidering only the flexure of the beam, the equation of free bending vibration in the interval $(0, L)$, except the ends $y=0, y=L$ and crack position $y=y_{0}$, has the form

$$
E J \frac{\partial^{4} W(y, t)}{\partial y^{4}}+\rho F \frac{\partial^{2} W(y, t)}{\partial t^{2}}=0 .
$$

The function $W(y, t)$ satisfies boundary conditions at the ends of beam and compatibility condition for displacements, moments and shear forces of both segments at the crack

$$
\begin{gathered}
W\left(y_{0}-0, t\right)=W(x+0, t) ; \\
W^{\prime \prime}(x-0, t)=W^{\prime \prime}(x+0, t) ; \\
E J W^{\prime \prime \prime}\left(y_{0}-0, t\right)=E J W^{\prime \prime \prime}\left(y_{0}+0, t\right) ; \\
\nu W^{\prime}\left(y_{0}-0, t\right)+E J W^{\prime \prime}\left(y_{0}-0, t\right)=\nu W^{\prime}\left(y_{0}+0, t\right) .
\end{gathered}
$$


The notation $y_{0}-0$ and $y_{0}+0$ mean that they belong to segments 1,2 respectively in both sides of the crack position.

By the transformation $\varsigma=y / L-0.5$ the equation (2.1) becomes

$$
E J \frac{\partial^{4} W(\zeta, t)}{\partial \zeta^{4}}+\rho F L^{4} \frac{\partial^{2} W(\zeta, t)}{\partial t^{2}}=0
$$

with the condition (2.2), now taken the form

$$
\begin{gathered}
W(x-0, t)=W(x+0, t) ; \\
W^{\prime \prime}(x-0, t)=W^{\prime \prime}(x+0, t) ; \\
W^{\prime \prime \prime}(x-0, t)=W^{\prime \prime \prime}(x+0, t) ; \\
W^{\prime}(x-0, t)+\beta W^{\prime \prime}(x-0, t)=W^{\prime}(x+0, t)
\end{gathered}
$$

where $x=y_{0} / L-0.5$ and $\beta=E J / \nu L$.

Assuming $W(\zeta, t)=\phi(\zeta) \sin \omega t$, where $\omega$ - natural frequency and $\phi(\zeta)$ - mode shape, last equation and condition lead to

$$
\begin{gathered}
\phi^{(I V)}(\zeta)-\lambda^{4} \phi(\zeta)=0 ; \quad-0.5 \leq \zeta \leq 0.5 ; \\
\lambda^{4}=L^{4} \omega^{2} \frac{\rho F}{E J}
\end{gathered}
$$

and

$$
\begin{gathered}
\phi(x-0)=\phi(x+0) ; \quad \phi^{\prime \prime}(x-0)=\phi^{\prime \prime}(x+0) ; \quad \phi^{\prime \prime \prime}(x-0)=\phi^{\prime \prime \prime}(x+0) \\
\phi^{\prime}(x-0)+\beta \phi^{\prime \prime}(x-0)=\phi^{\prime}(x+0) .
\end{gathered}
$$

Suppose that at the ends of the beam, $\zeta= \pm 0.5$, boundary conditions are given as one of the well known classical cases, for example, fixed ends. In general, bending vibration mode shape of this beam can be written in the form:

$$
\phi(\varsigma)=\left\{\begin{array}{ll}
C_{1} L_{1}(\zeta)+C_{2} L_{2}(\zeta)=\phi_{1}(\zeta), & -0.5 \leq \zeta<x \\
C_{3} L_{3}(\zeta)+C_{4} L_{4}(\zeta)=\phi_{2}(\zeta), & x<\varsigma \leq 0.5
\end{array} .\right.
$$

Functions $L_{i}(\zeta), i=1, \ldots, 4$ are determined by boundary condition at the ends and all of them satisfy equation (these functions for various boundary conditions are given in Appendix 1):

$$
\frac{d^{4}}{d \zeta^{4}}\left\{L_{i}(\zeta)\right\}-\lambda^{4} L_{i}(\zeta)=0
$$

$C=\left\{C_{1}, C_{2}, C_{3}, C_{4}\right\}^{T}$ are constants determined together with so-called frequency parameter $\lambda$ from compatibility condition at the $x$

$$
\begin{aligned}
\phi_{1}(x)=\phi_{2}(x) ; \quad \phi_{1}^{\prime \prime}(x) & =\phi_{2}^{\prime \prime}(x) ; \quad \phi_{1}^{\prime \prime \prime}(x)=\phi_{2}^{\prime \prime \prime}(x) \\
\phi_{1}^{\prime}(x)+\beta \phi_{1}^{\prime \prime}(x) & =\phi_{2}^{\prime}(x)
\end{aligned}
$$

where the prime denotes differentiation with respect to 5 .

Substituting (2.3) into (2.4) yields:

$$
A(\lambda, x, \beta) C=0
$$


where matrix $A$ has the form:

$$
\begin{gathered}
A=\left\{\begin{array}{cccc}
L_{1}\left(\xi_{1}\right) & L_{2}\left(\xi_{1}\right) & -L_{3}\left(\xi_{2}\right) & -L_{4}\left(\xi_{2}\right) \\
L_{1}^{\prime}\left(\xi_{1}\right)+\beta \lambda L_{1}^{\prime \prime}\left(\xi_{1}\right) & L_{2}^{\prime}\left(\xi_{1}\right)+\beta \lambda L_{2}^{\prime \prime}\left(\xi_{1}\right) & -L_{3}^{\prime}\left(\xi_{2}\right) & -L_{4}^{\prime}\left(\xi_{2}\right) \\
L_{1}^{\prime \prime}\left(\xi_{1}\right) & L_{2}^{\prime \prime}\left(\xi_{1}\right) & -L_{3}^{\prime \prime}\left(\xi_{2}\right) & -L_{4}^{\prime \prime}\left(\xi_{2}\right) \\
L_{1}^{\prime \prime \prime}\left(\xi_{1}\right) & L_{2}^{\prime \prime \prime}\left(\xi_{1}\right) & -L_{3}^{\prime \prime \prime}\left(\xi_{2}\right) & -L_{4}^{\prime \prime \prime}\left(\xi_{2}\right)
\end{array}\right\} \\
\xi_{1}=\lambda(x+0.5) ; \quad \xi_{2}=\lambda(x-0.5)
\end{gathered}
$$

For existence of $C=\left\{C_{1}, C_{2}, C_{3}, C_{4}\right\}^{T}, \lambda$ must satisfy equation:

$$
\operatorname{det} A(\lambda, x, \beta)=F(\lambda, x, \beta)=0,
$$

called frequency equation. Frequency parameter $\lambda$, as a solution of $(2.7)$, is a function of damage parameters $x, \beta$ :

$$
\lambda=\lambda(x, \beta),
$$

and the natural frequency of the beam will be:

$$
\omega=\sqrt{\frac{E J}{\rho F}}\left(\frac{\lambda}{L}\right)^{2} \quad \text { or } \quad f=\frac{1}{2 \pi} \sqrt{\frac{E J}{\rho F}}\left(\frac{\lambda}{L}\right)^{2} .
$$

Introducing matrices:

$$
A_{0}(\lambda, x)=\left\{\begin{array}{llll}
L_{1}\left(\xi_{1}\right) & L_{2}\left(\xi_{1}\right) & -L_{3}\left(\xi_{2}\right) & -L_{4}\left(\xi_{2}\right) \\
L_{1}^{\prime}\left(\xi_{1}\right) & L_{2}^{\prime}\left(\xi_{1}\right) & -L_{3}^{\prime}\left(\xi_{2}\right) & -L_{4}^{\prime}\left(\xi_{2}\right) \\
L_{1}^{\prime \prime}\left(\xi_{1}\right) & L_{2}^{\prime \prime}\left(\xi_{1}\right) & -L_{3}^{\prime \prime}\left(\xi_{2}\right) & -L_{4}^{\prime \prime}\left(\xi_{2}\right) \\
L_{1}^{\prime \prime \prime}\left(\xi_{1}\right) & L_{2}^{\prime \prime \prime}\left(\xi_{1}\right) & -L_{3}^{\prime \prime \prime}\left(\xi_{2}\right) & -L_{4}^{\prime \prime \prime}\left(\xi_{2}\right)
\end{array}\right\}
$$

and

$$
A_{1}(\lambda, \bar{x})=\left\{\begin{array}{cccc}
L_{1}\left(\xi_{1}\right) & L_{2}\left(\xi_{1}\right) & -L_{3}\left(\xi_{2}\right) & -L_{4}\left(\xi_{2}\right) \\
\lambda L_{1}^{\prime \prime}\left(\xi_{1}\right) & \lambda L_{2}^{\prime \prime}\left(\xi_{1}\right) & 0 & 0 \\
0 & 0 & -L_{3}^{\prime \prime}\left(\xi_{2}\right) & -L_{4}^{\prime \prime}\left(\xi_{2}\right) \\
L_{1}^{\prime \prime \prime}\left(\xi_{1}\right) & L_{2}^{\prime \prime \prime}\left(\xi_{1}\right) & -L_{3}^{\prime \prime \prime}\left(\xi_{2}\right) & -L_{4}^{\prime \prime \prime}\left(\xi_{2}\right)
\end{array}\right\}
$$

we get

$$
\begin{aligned}
& F_{0}(\lambda, x)=\operatorname{det} A_{0}(\lambda, x)=F(\lambda, x, 0), \\
& F_{1}(\lambda, x)=\operatorname{det} A_{1}(\lambda, x)=\frac{\partial F(\lambda, x, \beta)}{\partial \beta} .
\end{aligned}
$$

In fact, the first equality of (2.10) is evident by substituting $\beta=0$ into (2.6). The second one can be obtained by differentiating determinant $\operatorname{det} A(\lambda, x, \beta)$ with respect to $\beta$. Considering (2.10) as a differential equation of $F(\lambda, x, \beta)$ with initial condition at $\beta=0$, we have:

$$
F(\lambda, x, \beta)=F_{1}(\lambda, x) \beta+F_{0}(\lambda, x) .
$$

Thus, the frequency equation (2.7) can be rewritten as:

$$
\beta F_{1}(\lambda, x)+F_{0}(\lambda, x)=0 .
$$

From here, particular equations, corresponding limiting cases of damage will take the form:

$$
F_{0}(\lambda, x)=\operatorname{det} A_{0}(\lambda, x)=0,
$$


for undamaged beam, and:

$$
F_{1}(\lambda, x)=\operatorname{det} A_{1}(\lambda, x)=0,
$$

for other limiting case. Let $\lambda(\beta, x), \lambda^{0}, \lambda^{1}(x)$ be the roots of equations (2.12), (2.13) and (2.14) respectively.

3. Sensitivity of the frequencies

Let us consider, at first, equation (2.13). Differentiating function $F_{0}(\lambda, x)=\operatorname{det} A_{0}(\lambda, x)$ with respect to $x$ gives

$$
\frac{\partial F_{0}(\lambda, x)}{\partial x}=0 \text { or } F_{0}(\lambda, x)=F_{0}(\lambda) \text {. }
$$

Consequently, as well known the frequencies of undamaged beam do not depend on position $x$.

Since $\lambda(\beta, x)$ is a solution of $(2.12)$ we have

$$
\beta F_{1}[\lambda(\beta, x), x]+F_{0}[\lambda(\beta, x)]=0,
$$

consequently

$$
\begin{aligned}
& \bar{F}_{1}(\beta, x)+\beta \bar{F}_{1 \lambda} \frac{\partial \lambda}{\partial \beta}+\bar{F}_{0 \lambda} \frac{\partial \lambda}{\partial \beta} \equiv 0, \quad \beta \bar{F}_{1 \lambda} \frac{\partial \lambda}{\partial x}+\beta \bar{F}_{1 x}+\bar{F}_{0 \lambda} \frac{\partial \lambda}{\partial x} \equiv 0 \\
& \bar{F}_{1}=F_{1}[\lambda(\beta, x), x]=\bar{F}_{1}(\beta, x), \quad \bar{F}_{1 \lambda}=\frac{\partial F_{1}}{\partial \lambda}[\lambda(\beta, x), x]=\bar{F}_{1 \lambda}(\beta, x), \\
& \bar{F}_{1 x}=\frac{\partial F_{1}}{\partial x}[\lambda(\beta, x), x]=\bar{F}_{1 x}(\beta, x), \quad \bar{F}_{0 \lambda}=\frac{\partial F_{0}}{\partial \lambda}[\lambda(\beta, x)]=\bar{F}_{0 \lambda}(\beta, x)
\end{aligned}
$$

(with the functions $\bar{F}_{1 \lambda}, \bar{F}_{1 x}, \bar{F}_{0 \lambda}$ calculated from given functions $F_{0}, F_{1}$ )

In the end, we get

$$
\begin{aligned}
& \frac{\partial \lambda}{\partial \beta} \equiv R_{\beta}(\beta, x)=-\frac{\bar{F}_{1}(\beta, x)}{\beta \bar{F}_{1 \lambda}(\beta, x)+\bar{F}_{0 \lambda}(\beta, x)}, \\
& \frac{\partial \lambda}{\partial x} \equiv R_{x}(\beta, x)=-\frac{\bar{F}_{1 x}(\beta, x)}{\beta \bar{F}_{1 \lambda}(\beta, x)+\bar{F}_{0 \lambda}(\beta, x)}
\end{aligned}
$$

In the case, if $\beta=\beta_{0}+\delta \beta, x=x_{0}+\delta x$, we get approximately

$$
\Delta \lambda=R_{\beta}\left(\beta_{0}, x_{0}\right) \delta \beta+R_{x}\left(\beta_{0}, x_{0}\right) \delta x .
$$

This equation may be useful for detection of the crack parameters if the changes of the frequencies will be given.

Furthermore, let us consider the position $x$ of crack, at which the change of the frequency parameter $\lambda(\beta, x)$ in comparison with one of uncracked beam $\lambda^{0}$ reaches extremum.

At first, we consider the crack position $x^{*}$, for which the crack magnitude does not affect the natural frequencies of the beam.

Theorem 1. The critical points $x^{*}$ can be found from the equation

$$
F_{1}\left(\lambda^{0}, x^{*}\right)=0
$$

where $\lambda^{0}$ is the solution of (2.13), i.e. $F_{0}\left(\lambda_{0}\right)=0$. 
In fact, it means that at such position $x^{*}$ the solution of the equations $(2.12) \lambda\left(\beta, x^{*}\right)=$ const $\forall \beta$ or

$$
\frac{\partial \lambda}{\partial \beta} \equiv R_{\beta}\left(\beta, x^{*}\right)=-\frac{\bar{F}_{1}\left(\beta, x^{*}\right)}{\beta \bar{F}_{1 \lambda}\left(\beta, x^{*}\right)+\bar{F}_{0 \lambda}\left(\beta, x^{*}\right)}=0, \quad \forall \beta .
$$

From here it follows that $F_{1}\left[\lambda\left(\beta, x^{*}\right), x^{*}\right]=0, \forall \beta$ and due to (3.2) it yields $F_{0}\left[\lambda\left(\beta, x^{*}\right)\right]=0$. Therefore, it must be $\lambda\left(\beta, x^{*}\right)=\lambda^{0}$. Thus, we have

$$
\lambda\left(\beta, x^{*}\right)=\lambda^{1}\left(x^{*}\right)=\lambda^{0}, \quad \forall \beta .
$$

So, at the position $x^{*}$ equations $(2.13),(2.14)$ have the same solution $\lambda^{0}$. The position $x^{*}$, if it exists, is called critical point for given $\lambda^{0}$. Certainly, critical point is related with every solution $\lambda^{0}$ separately, i.e. various solution $\lambda^{0}$ of the equation (2.13) may have different critical points. In addition, a given solution may have either no or more than one critical point. On the other hand, critical points are that, at which corresponding bending moment is equal to zero. Because of this, damage occurred at the critical points of a mode has no influence on the corresponding natural frequency.

Now we investigate those points in the beam, at which the change of frequencies is a maximum for a value of crack magnitude $\beta \neq 0$. Such a position denoted by $x^{m}$. will be called the most sensitive.

Theorem 2. The most sensitive position $x^{m}$ of a crack is that, where for given $\beta>0$ the equations (2.12) and

$$
F_{1 x}(\lambda, x)=0
$$

have the common solution with respect to $\lambda$.

As shown in the Theorem 1, minimal change of natural frequencies, which are equal to zero, has appeared at the critical points and corresponds to $\beta=0$, while common solution of the equations (2.12) and (3.5) may contain the critical points only in the case of uncracked beam $(\beta=0)$. When beam has cracked $(\beta>0)$ the common solution of the mentioned equations consist of only the most sensitive points.

Likely to the critical crack position, the most sensitive crack position is also related to each frequency differently. Every frequency has itself most sensitive to the crack position, so that knowing these positions may be helpful for crack detection.

\section{Numerical examples}

For illustration, here three wellknown cases of boundary supports (simply supported, clamped both ends and cantilever) are investigated numerically. Solutions of equations (2.13), (3.1) are calculated and given in the Table 1. In particularity, for simply supported beam analytical solutions of the equations are

$$
\lambda_{k}^{0}=k \pi, \quad k=1,2, \ldots ; \quad x_{k m}=-0.5+m / k, \quad m=1, \ldots, k-1 .
$$

General solution of the equation (2.12) and functions (3.2) have been calculated as a function of $x$ for different values of $\beta$. Graphics of the obtained functions are presented in Fig. 2, 3, from which one can make the following conclusions:

- Straight lines corresponding zero crack magnitude (undamaged) really show the independence of the frequencies on the position $x$,

- Frequencies decrease with the growth of the crack magnitude at any position of the crack. 
a) Simply supported beam

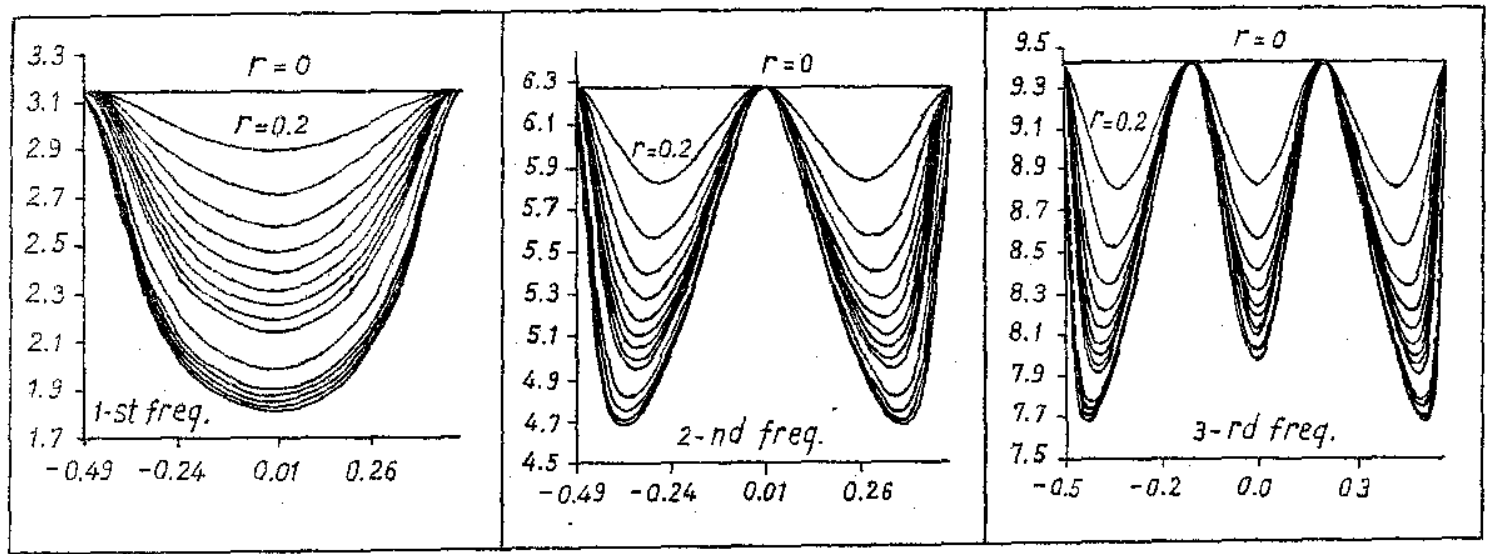

b) Clamped ends

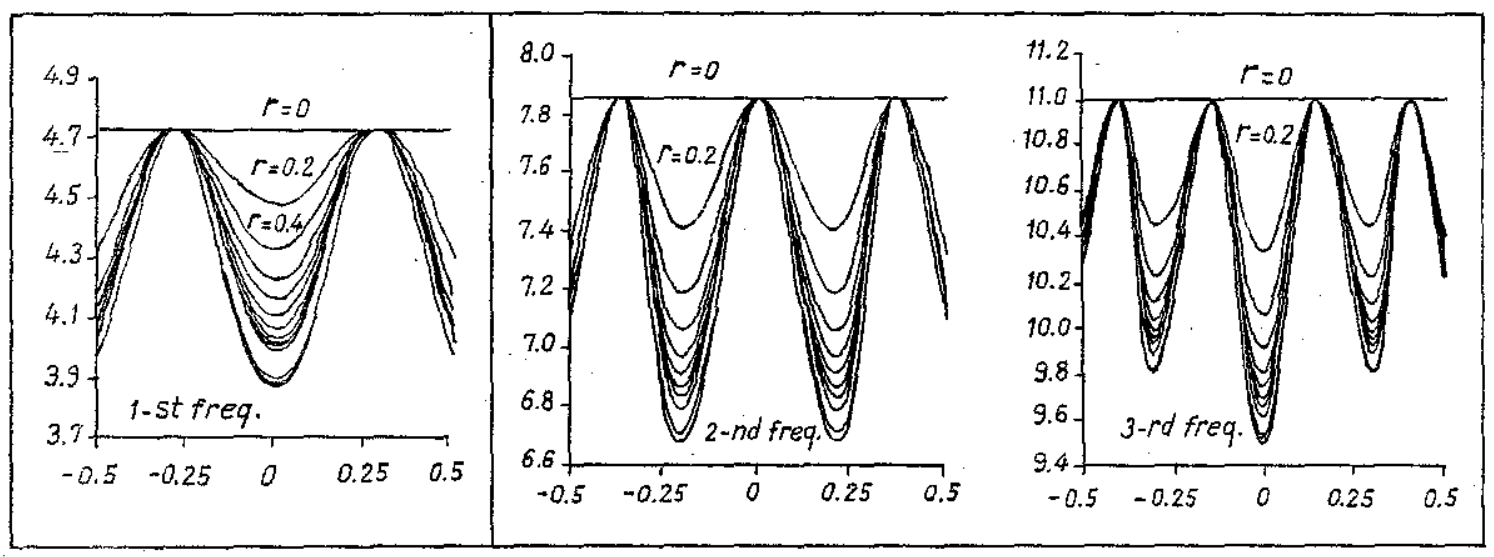

c) Cantilever

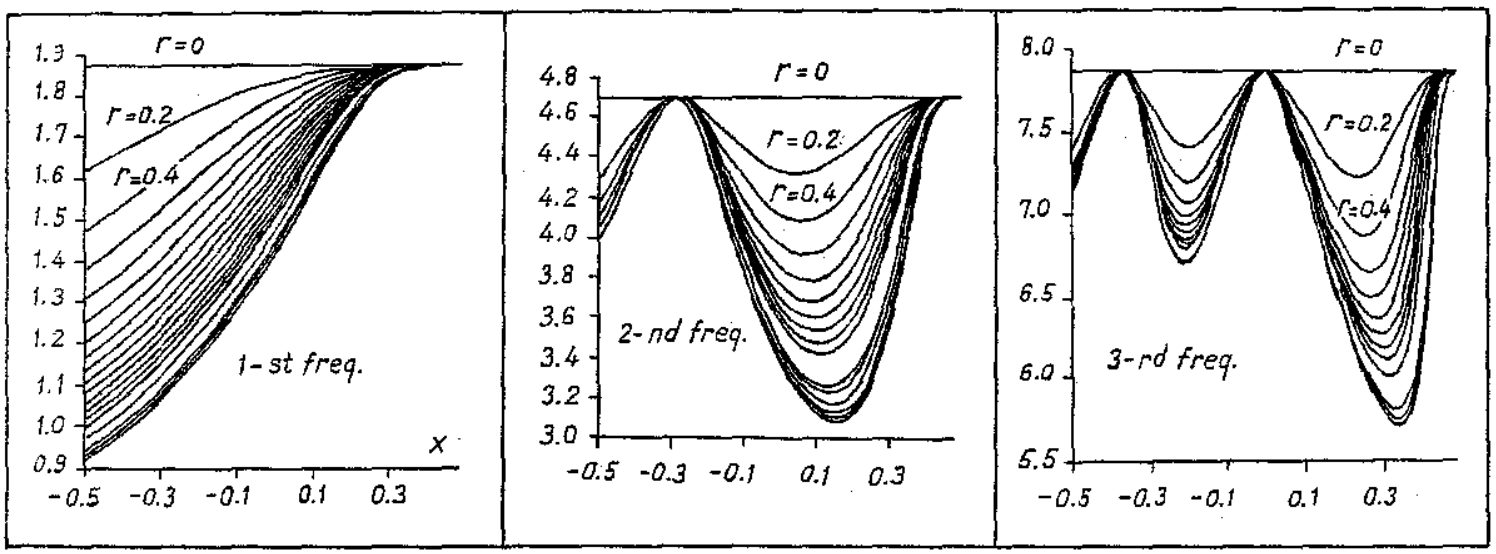

Fig. 2. The dependence of three frequencies on the crack position $x$ for different values of crack magnitude (from 0.0 to 4.0) in different cases of the boundary conditions 
a) Simply supports

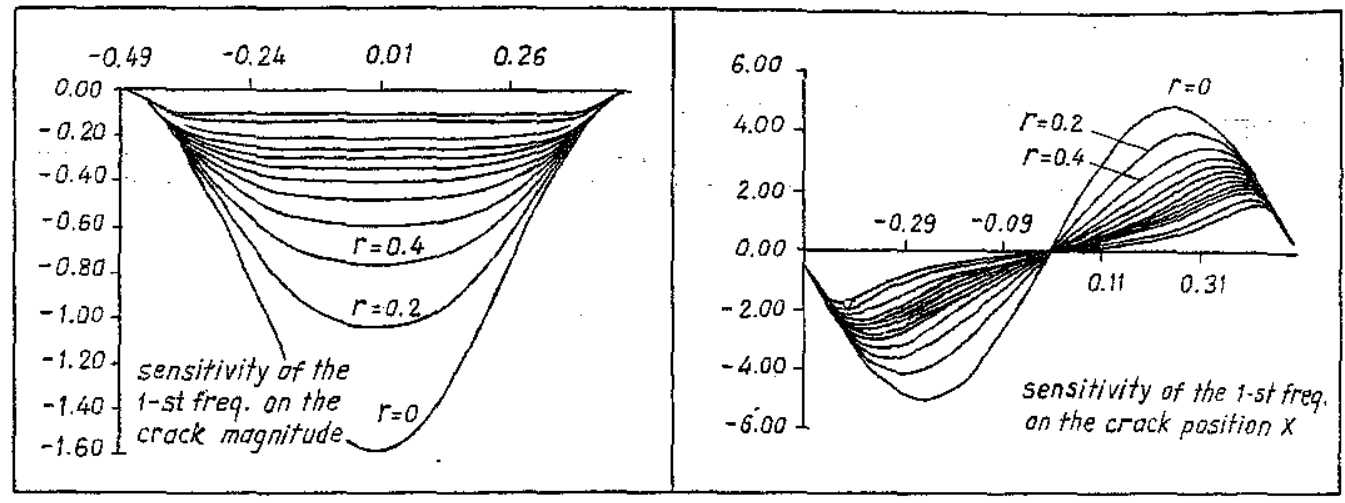

b) Clamped ends

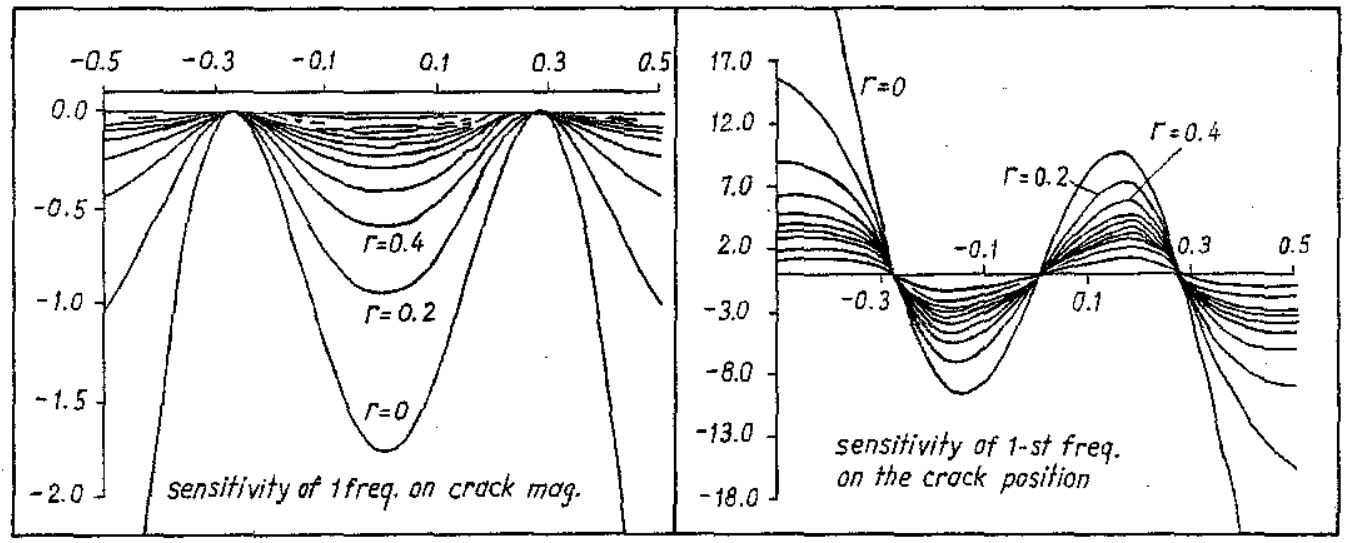

\section{c) Cantilever}
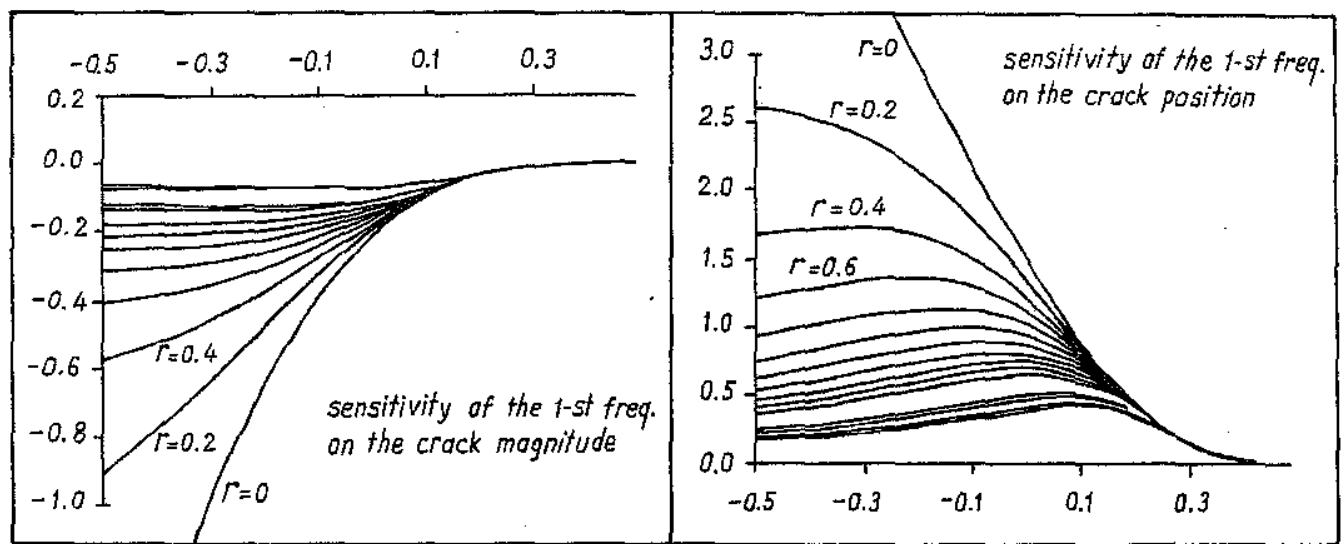

Fig. 3. Sensitivity of the first frequency on the crack parameters in dependence on the crack position for various values of the crack magnitude 
- The existence of the critical and most sensitive points is clearly shown in the figure, they validate the theorem 1,2 and given in Table 1.

- In addition, graphics in Fig. 3 show also the positions of crack, at which for given $\beta$ the change of the frequencies will be maximum and the more crack magnitude the lower frequencies.

Table 1. Three first frequencies of undamaged beam and corresponding their critical points in different cases of boundary supports

\begin{tabular}{|c|c|c|c|c|c|c|}
\hline \multirow{2}{*}{$\begin{array}{l}\text { Type of } \\
\text { boundary } \\
\text { condition }\end{array}$} & \multirow{2}{*}{$\begin{array}{l}\text { Value of the } \\
\text { freq. parameters } \\
\text { of intact beam }\end{array}$} & \multicolumn{4}{|c|}{ Critical points } & \multirow{2}{*}{$\begin{array}{c}\text { Total } \\
\text { quan- } \\
\text { tity }\end{array}$} \\
\hline & & 1 & $\dot{2}$ & 3 & 4 & \\
\hline \multirow{3}{*}{$\begin{array}{l}\text { 1. Simply } \\
\text { supported } \\
\text { beam }\end{array}$} & $\lambda_{1}^{0}=3.14159$ & - & - & - & - & 0 \\
\hline & $\lambda_{2}^{0}=6.28319$ & 0.9 & - & - & - & 1 \\
\hline & $\lambda_{3}^{0}=9.42478$ & -0.1666 & +0.1666 & - & - & 2 \\
\hline \multirow{3}{*}{ 2. Cantilever } & $\lambda_{1}^{0}=1.87510$ & - & - & - & - & 0 \\
\hline & $\lambda_{2}^{0}=4.69409$ & -0.2836 & - & - & - & 1 \\
\hline & $\lambda_{3}^{0}=7.85474$ & -0.3673 & $-3.9 \mathrm{E}-3$ & - & - & 2 \\
\hline \multirow{3}{*}{$\begin{array}{l}\text { 3. Beam } \\
\text { with } \\
\text { fixed ends }\end{array}$} & $\lambda_{1}^{0}=4.73004$ & -0.2759 & +0.2759 & - & - & 2 \\
\hline & $\lambda_{2}^{\hat{0}}=7.85318$ & -0.3674 & 0.0 & +0.3674 & - & 3 \\
\hline & $\lambda_{3}^{0}=10.9954$ & -0.4046 & -0.1432 & +0.1432 & +0.4046 & 4 \\
\hline
\end{tabular}

\section{Conclusion}

The main results obtained in this study can be underlined as follows:

1. While the previously published papers have dealt with the cracked beam in particular cases of the boundary supports, the present work gives general equations for analyzing natural frequencies in dependence on the crack parameters. These equations can be efficiently used to detect the position and magnitude of the crack by measurements of natural frequencies.

2. The equations established have been used for investigating the natural frequencies as function of crack parameters in the classical cases of boundary conditions. Here, there have been carried out the positions of the crack, at which the crack magnitude does not influence on the natural frequencies. This fact is useful for detection of the crack position if a changeless of some measured frequencies in comparison with those of the undamaged beam will be recognized.

3. The numerical results confirm the efficiency of the equations and exactness of the theoretical results. One shows also that the change of the frequencies is more considerable at the small values of crack magnitude.

4. The crack detection problem using the equations will be investigated in an other paper.

This publication is completed with financial support from the National Basic Research Programme in Natural Sciences. 
Appendix 1. Functions $L_{j}(x), j=1, \ldots, 4$

Introducing functions

$$
\begin{array}{ll}
K_{1}(\xi)=\sin \xi-\operatorname{sh} \xi ; & K_{3}(\xi)=\sin \xi+\operatorname{sh} \xi \\
K_{2}(\xi)=\cos \xi-\operatorname{ch} \xi ; & K_{4}(\xi)=\cos \xi+\operatorname{ch} \xi
\end{array}
$$

satisfying

$$
K_{1}^{\prime}=K_{2}, \quad K_{2}^{\prime}=-K_{3}, \quad K_{3}^{\prime}=K_{4}, \quad K_{4}^{\prime}=-K_{1}
$$

the functions $L_{1}(\xi), L_{2}(\xi), L_{3}(\xi), L_{4}(\xi)$ in matrices $A_{1}, A_{0}$ for different cases of boundary conditions have the following form

1. Simply supported beam

$$
\begin{array}{rlrl}
L_{1}(\xi) & =L_{3}(\xi)=\sin \xi ; & & L_{2}(\xi)=L_{4}(\xi)=\operatorname{sh} \xi \\
L_{1}^{\prime}(\xi)=L_{3}^{\prime}(\xi)=\cos \xi ; & & L_{2}^{\prime}(\xi)=L_{4}^{\prime}(\xi)=\operatorname{ch} \xi \\
L_{1}^{\prime \prime}(\xi)=L_{3}^{\prime \prime}(\xi)=-\sin \xi ; & L_{2}^{\prime \prime}(\xi)=L_{4}^{\prime \prime}(\xi)=\operatorname{sh} \xi \\
L_{1}^{\prime \prime \prime}(\xi)=L_{3}^{\prime \prime \prime}(\xi)=-\cos \xi ; & L_{2}^{\prime \prime \prime}(\xi)=L_{4}^{\prime \prime \prime}(\xi)=\operatorname{ch} \xi
\end{array}
$$

2. Beam with fixed ends

$$
\begin{array}{rlrl}
L_{1}(\xi) & =L_{3}(\xi)=K_{1}(\xi) ; & & L_{2}(\xi)=L_{4}(\xi)=K_{2}(\xi) ; \\
L_{1}^{\prime}(\xi)=L_{3}^{\prime}(\xi)=K_{2}(\xi) ; & & L_{2}^{\prime}(\xi)=L_{4}^{\prime}(\xi)=-K_{3}(\xi) ; \\
L_{1}^{\prime \prime}(\xi)=L_{3}^{\prime \prime}(\xi)=-K_{3}(\xi) ; & L_{2}^{\prime \prime}(\xi)=L_{4}^{\prime \prime}(\xi)=-K_{4}(\xi) ; \\
L_{1}^{\prime \prime \prime}(\xi)=L_{3}^{\prime \prime \prime}(\xi)=-K_{4}(\xi) ; & L_{2}^{\prime \prime \prime}(\xi)=L_{4}^{\prime \prime \prime}(\xi)=K_{1}(\xi)
\end{array}
$$

In this case, we have a symmetrical function $F_{1}(\lambda, x)$ with respect to $x$.

3. Cantilever beam

$$
\begin{array}{rlll}
L_{1}(\xi)=K_{1}(\xi) ; & L_{2}(\xi)=K_{2}(\xi) ; & L_{3}(\xi)=K_{3}(\xi) ; & L_{4}(\xi)=K_{4}(\xi) ; \\
L_{1}^{\prime}(\xi)=K_{2}(\xi) ; & L_{2}^{\prime}(\xi)=-K_{3}(\xi) ; & L_{3}^{\prime}(\xi)=K_{4}(\xi) ; & L_{4}^{\prime}(\xi)=-K_{1}(\xi) ; \\
L_{1}^{\prime \prime}(\xi)=-K_{3}(\xi) ; & L_{2}^{\prime \prime}(\xi)=-K_{4}(\xi) ; & L_{3}^{\prime \prime}(\xi)=-K_{1}(\xi) ; & L_{4}^{\prime \prime}(\xi)=-K_{2}(\xi) ; \\
L_{1}^{\prime \prime \prime}(\xi)=-K_{4}(\xi) ; & L_{2}^{\prime \prime \prime}(\xi)=K_{1}(\xi) ; & L_{3}^{\prime \prime \prime}(\xi)=-K_{2}(\xi) ; & L_{4}^{\prime \prime \prime}(\xi)=K_{3}(\xi)
\end{array}
$$

\section{References}

1. Yuen M. M. A numerical study of the eigenparameters of a damaged cantilever. Journal of Sound and Vibration, 103, 1985.

2. Adam R. D., Cawley P., Pye C. J. and Stone B. J. A vibration technique for non-destructively assessing the integrity of structures. Journal of Mechanical Engineering Science 20, 2, 1978.

3. Dimarogonas A. D. Vibration Engineering. St. Paul, Minnesota: West Publishers, 1976.

4. Dimarogonas A. D. and Paipetis S. A. Analytical Methods in Rotor Dynamics, London: Elsevier Applied Science 1983.

5. Rizos P. F., Aspragathos N. and Dimarogonas A. D. Identification of crack location and magnitude in a cantilever beam from the vibration modes. Journal of Sound and Vibration $138,1990$. 
6. Ostach owicz W. M. and Krawczuk M. Analysis of the effect of crack on the natural frequencies of a cantilever beam. Journal of Sound and Vibration 150, 1991.

7. Narkis Y. Identification of crack location in vibrating simply supported beams. Journal of Sound and Vibration 172 (4), 1994.

8. Morassi A. Crack-induced changes in eigenparameters of beam structures. Journal of Engineering Mechanics 119, 1993.

9. Shen M. H.H. and Pierre C. Natural Modes of Bernoulli-Euler beams with symmetric crack. Journal of Sound and Vibration 138, 1990.

10. Christides S. and Barr A. D. One-dimensional theory of cracked Bernoulli-Euler beams. International Journal of the Mechanical Sciences, 26 (11/12) 1984.

Received February 24, 1997

\section{PHÂN TÍCH TẦN SỐ RIÊNG CỬA DẦM CÓ VẾT NỨT}

Trên cớ sở mô hình vết nứt được mô tả bằng một lò xo xoăn nối hai phần dầm mà vết nứt tạo nên:

- Xây dựng được các phương trình tần số tổng quát cho các điều kiện biên khác nhau và phụ thuộc vào các tham số vết nứt như vị trí và mức độ nứt;

- Phân tích sự phụ thuộc của tần số riêng đối với các điều kiện biên khác nhau vào các tham số vết nứt;

- Sự phụ thuộc này được nghiên cứu bằng số và được minh họa bằng các bức tranh đầy đủ qua các đồ thị và bảng biểu.

Những kết quà này là cơ sơ quan trọng cho việc phát hiện và xử lý các vết nứt trong các kết cấu công trình thực như cầu, cột điện hay các nhà cao tầng v.v... 